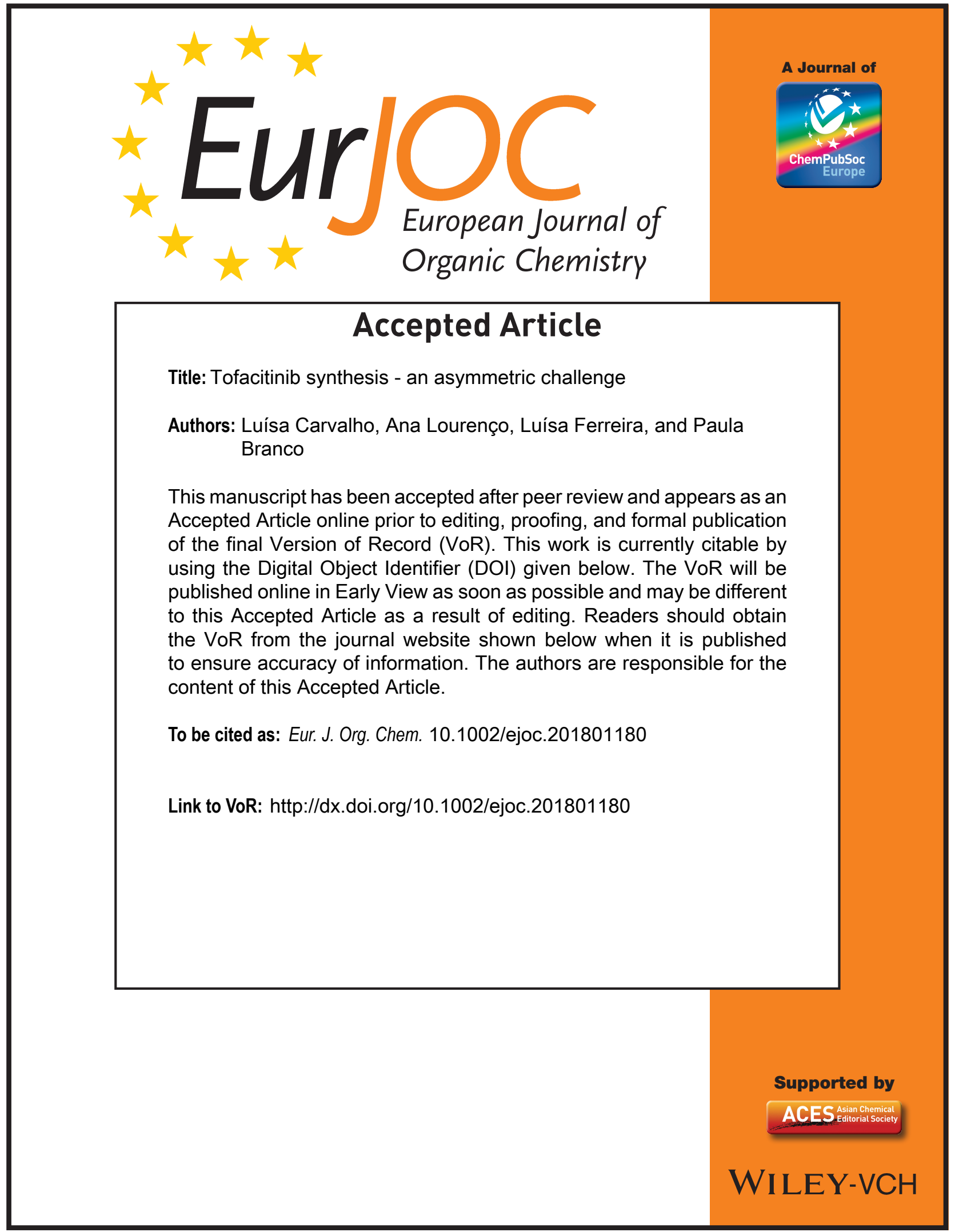


WILEY-VCH

\title{
Tofacitinib synthesis - an asymmetric challenge
}

\author{
Luísa C. R. Carvalho, ${ }^{*[a]}$ Ana Lourenço, ${ }^{[a]}$ Luísa Maria Ferreira ${ }^{[a]}$ and Paula Sério Branco ${ }^{[a]}$
}

Abstract: Tofacitinib is a Janus activated kinase (JAK) inhibitor approved for the treatment of rheumatoid arthritis and active psoriatic arthritis. Its synthesis normally involves long synthetic sequences due to the chirality associated to the piperidine ring. This review is a comprehensive analysis of the different synthetic methods used to prepare this active pharmaceutical ingredient (API), covering the related journal and patent literature.

\section{Introduction}

Janus activated kinases (JAKs) are a family of receptorassociated tyrosine kinases involved in several physiological functions such as immune response and are related to autoimmune and inflammatory diseases. ${ }^{[1],[2]}$ JAK1/2 and TYK2 (tyrosine kinase 2) are ubiquitously expressed and mediate diverse physiological processes, while JAK3 is only expressed in cells of the lymphohematopoietic lineage, limiting its function to the immune system. ${ }^{[1]}$ Thus, due to the observed immunodeficiency resulting from the absence of JAK3, it was assumed that selective JAK3 inhibitors would act as potent immunosuppressive agents. ${ }^{[3]}$ Tofacitinib (1) was developed by Pfizer, ${ }^{[4],[5]}$ and was initially believed to be a selective JAK3 inhibitor. ${ }^{[6]}$ However, subsequent studies revealed its poor JAK3 selectivity, also inhibiting JAK1 and JAK2. ${ }^{[7]}$ Nonetheless, JAK3 selective inhibitors seem to have a lower efficiency when compared to tofacitinib. ${ }^{[7],[8]}$ It was claimed that the balance of JAK kinases inhibition casually achieved with $\mathbf{1}$, may actually improve its efficacy towards several therapeutic indications.

Luísa C. R. Carvalho obtained her Ph.D. in Sustainable Chemistry from Universidade NOVA de Lisboa (FCT/UNL) in 2014. After her studies, she worked as a post-doctoral researcher at FCT/UNL on the development of orthogonal protection strategies for oligosaccharides and on biopolymers modification. In 2016, she joined a research project in collaboration with a pharmaceutical company to develop novel synthetic strategies to produce active pharmaceutical ingredients.
Luísa Maria Ferreira received her Ph.D. in Organic Chemistry from NOVA University Lisbon in 1994. Since then, she has been teaching and supervising students from the same university and is a member of the research center LAQV@REQUIMTE. She has been working in projects characterized by the relevance of the multidisciplinary aspects of organic chemistry in problems of conservation sciences, food science, toxicological challenges, or total synthesis of bioactive targets, always with the focus on developing new synthetic methodologies.

Ana Lourenço completed her Ph.D. in Organic Chemistry at the NOVA University of Lisbon in 1992. She has developed her academic career at this university teaching Organic Chemistry and Biosynthesis of Natural Products and supervising students. She is a member of the LAQV@REQUIMTE research center where she works in the chemistry of natural products with biological activity from terrestrial and marine sources. The main research interests focus on the discovery of new structures with antiinflammatory action and anti-cancer activity, and valorization of terrestrial natural resources.

Paula Branco received her Ph.D. in Organic Chemistry from NOVA University Lisbon in 1992. She is an Assistant Professor at the same faculty, teaching courses related to organic chemistry, organic synthesis and mechanisms at both undergraduate and graduate levels. Her scientific interest is focused on organic chemistry namely the "target-oriented organic synthesis" and has been diversified into several areas, always based on the design and synthesis of new molecules which can contribute to interdisciplinary solutions.
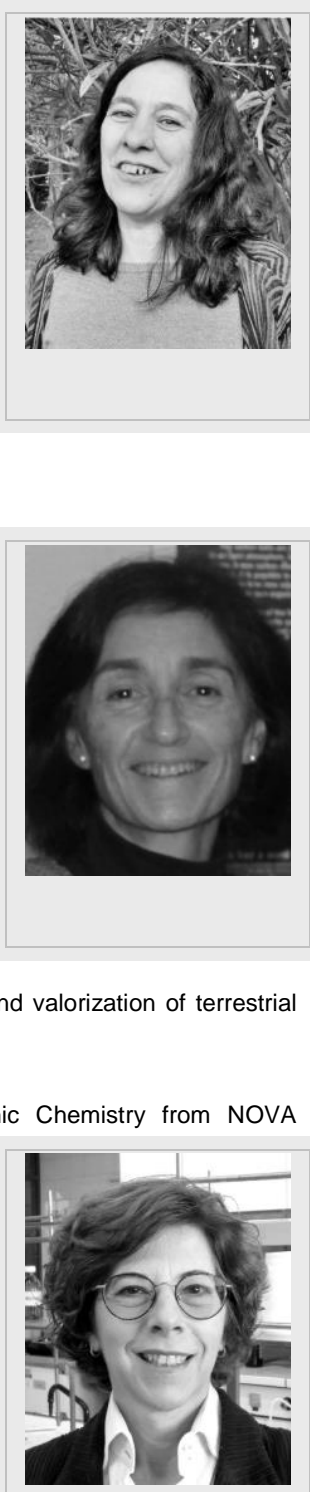

[a] Dr. L. C. R. Carvalho, Prof. Dr. A. Lourenço; Prof. Dr. L. M Ferreira; Prof. Dr. P. S. Branco

Departamento de Química, Faculdade de Ciências e Tecnologia, Universidade NOVA de Lisboa, 2829-516 Caparica, Portugal

E-mail: luisa_carvalho@campus.fct.unl.pt

http://www.requimte.pt/laqv/people/luisacarvalho 
<smiles>[R12]C1CC[C@@H](C)[C@H](NC)C1</smiles>

Figure 1. Tofacitinib (1) structure and retrosynthetic analysis.

Tofacitinib (1) was the first JAK inhibitor approved by the US Food and Drug Administration for the treatment of rheumatoid arthritis (2012), and very recently (2017) it was approved for active psoriatic arthritis. It is produced and commercialized by Pfizer under the brand name XeljanzTM and Xeljanz XRTM (tofacitinib citrate). It has also been evaluated for the treatment of other pathologies, such as inflammatory bowel diseases and to prevent transplant rejection. ${ }^{[9],[10]}$

Tofacitinib (1), [3-[(3R,4R)-4-methyl-3-[methyl(7H-pyrrolo[2,3-d] pyrimidin-4-yl)amino]piperidin-1-yl]-3-oxopropanenitrile] can be fragmented into two main synthons: the 4-substituted pyrrolo[2,3d]pyrimidine (blue) and a piperidine analogue that could lead to the required 3-((3R,4R)-4-methyl-3-(methylamino)piperidin-1-yl)3-oxopropanenitrile moiety (yellow) (Figure 1). Depending on the chosen strategy, the heterocyclic structure can be usually achieved in a fast manner from commercially available starting materials. However, the demand for the piperidine moiety on a kilogram scale, allied to its challenging structure comprising two asymmetric centers, required the development of efficient procedures that could be applied to an industrial scale. Moreover, its preparation usually requires a final chiral resolution step, which usually implies additional yield losses. Thus, most of the described procedures to produce $\mathbf{1}$ are focused on novel strategies to assemble the piperidine fragment, rather than the construction of the overall heterocyclic structure. Thus, it can be noticed the plethora of starting materials that were used to attain this intermediate (Figure 2).

This review covers the literature concerning tofacitinib synthesis, particularly the challenges found in the asymmetric synthesis of the piperidine synthon, which can aid and stimulate further studies towards the preparation of relevant structures possessing similar demands.

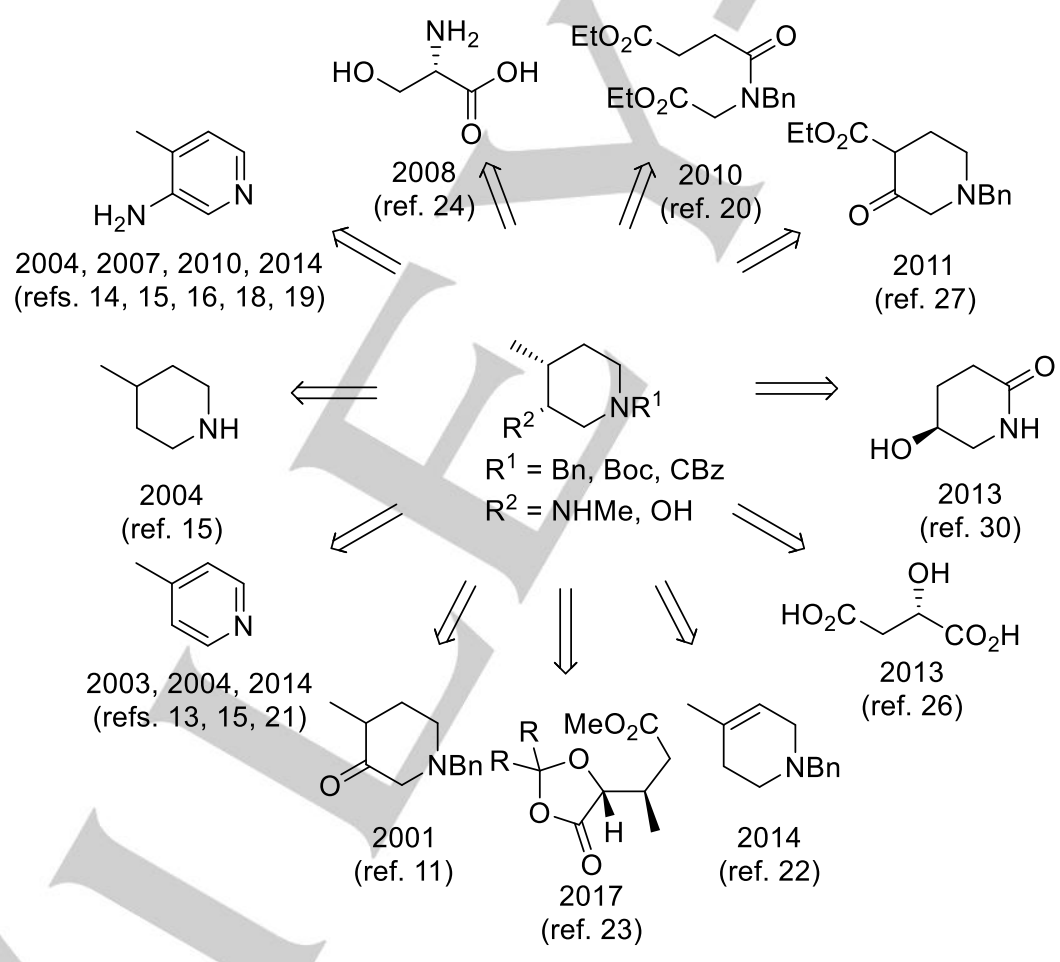

Figure 2. Starting materials described in the literature to assemble the piperidine fragment. 


\section{Piperidine moiety assembly}

The first description of $\mathbf{1}$ was disclosed in 2001 by Pfizer. ${ }^{[11]}$ This early report discloses the preparation of $\mathbf{1}$ as the corresponding diastereomers without further isolation. For that purpose, $\mathbf{3}$ was assembled from 1-benzyl-4-methyl-piperidin-3-one (2) by reductive amination and was obtained as a mixture of the corresponding four diastereomeric forms. Compound 2 was prepared from a piperidone analogue or from isoprene, involving synthetic procedures unfeasible in large scale. ${ }^{[12]}$
One year later, Pfizer reported the chiral salt resolution of $\mathbf{3}$, which was first isolated as the corresponding hydrochloric salt $\mathbf{4}$ followed by treatment with di-p-toluyl-L-tartaric acid (L-DTTA) or (+)phencyphos to obtain the corresponding salts 5 and $\mathbf{6}$ with an enantiomeric excess (ee) of $99 \%$ (Scheme 1). ${ }^{[4]}$ Due to the simple strategy employed to form $\mathbf{1}$ using the benzylated derivative $\mathbf{5}$ (or its neutral form), most of the subsequently described methodologies explores the preparation of this key intermediate.

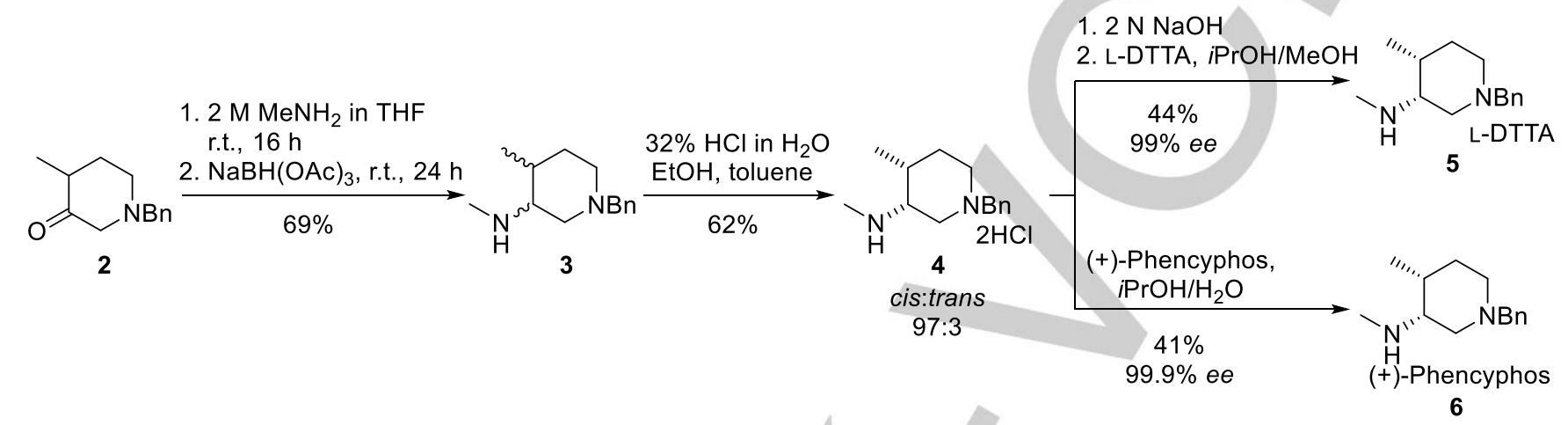

Scheme 1. Pfizer's approach (2002) to obtain intermediates 5 and 6. ${ }^{[4]}$

In 2003, Ripin et al. (Pfizer) reported the synthesis of $\mathbf{4}$ from picoline (7), as an alternative starting material (Scheme 2). ${ }^{[13]}$ The synthesis was optimized for a kilogram scale and started by the benzylation of 7 with benzyl chloride to produce a pyridinium salt, followed by reduction with sodium borohydride, to provide the tetrahydropyridine 8 in $94 \%$ purity. The subsequent hydroboration of $\mathbf{8}$ was tested under different conditions. It was verified that the use of $\mathrm{BF}_{3}$ etherate complex improved the reaction yield and that less hydrogen gas was generated during the work-up step. Moreover, to minimize the hydrogen liberated, the quench was performed in methanol in the presence of $10 \%$ calcium chloride in $0.2 \mathrm{~N} \mathrm{HCl}$ solution $(\mathrm{pH} 2)$. The resulting alkylborane was oxidized under acidic conditions $(\mathrm{pH} 2)$ using hydrogen peroxide, without requiring extended reaction times at elevated temperature. The authors claimed that the method required lower volumes of solvent compared to the procedure employing Oxone. The corresponding alcohol was isolated as the tosylate salt (9) in high purity. Due to the reaction scale, the authors selected a
$\mathrm{SO}_{3}$.pyridine oxidation procedure to attain 2 . The $\mathrm{pH}$ of the workup was kept around 10 to maximize product recovery. Product 2 was obtained in $93 \%$ yield, being verified methylthiomethyl ether as the major contaminant $(6 \%)$. The reductive amination was performed using 4 equiv of methylamine and 1 equiv of HOAc to guarantee a rapid and complete conversion to the imine. Although stated that at a bench scale $\mathrm{NaB}(\mathrm{OAc})_{3} \mathrm{H}$ showed an improved selectivity compared to $\mathrm{NaBH}_{4}$, the scale-up described in the experimental section was performed using $\mathrm{NaBH}_{4}$. Compound 10 was obtained in $92 \%$ (86:14 cis:trans) along with $<4 \%$ of 9 and 5$8 \%$ of the methylthiomethyl ether as the major contaminants. The cis:trans ratio could be enhanced via successive recrystallizations to attain the hydrochloride salt 4 with a $d r 97.3: 2.7$. As reported in the previous Pfizer's patent, ${ }^{[4]}$ the product resolution was performed using L-DTTA without the need to isolate the free base. Moreover, it was reinforced that resolution requires the seeding with a salt of high ee and that despite the optimized procedure, the trans isomer is never effectively eliminated. 


\section{MICROREVIEW}

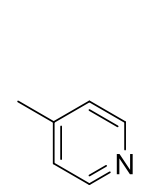

7

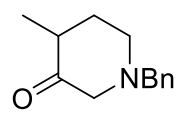

2
1. $\mathrm{BnCl}$, acetone,

$16 \mathrm{~h}, 55^{\circ} \mathrm{C}, 69 \%$

2. $\mathrm{NaBH}_{4}, \mathrm{EtOH}$

$\stackrel{10 \mathrm{~h}, 15^{\circ} \mathrm{C}, 73 \%}{\longrightarrow}$

8
1. $\mathrm{BF}_{3} . \mathrm{OEt}_{2}, \mathrm{BH}_{3}$. THF,

THF, $20^{\circ} \mathrm{C}, 14.5 \mathrm{~h}$

2. $17.5 \% \mathrm{H}_{2} \mathrm{O}_{2}, 19-22^{\circ} \mathrm{C}, 68 \mathrm{~h}$

3. $\mathrm{TsOH}$, acetone, -2 to $5^{\circ} \mathrm{C}, 1.5 \mathrm{~h}$

$88 \%$ over three steps

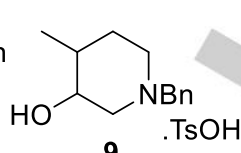

$\mathrm{SO}_{2} \cdot \mathrm{Py}, \mathrm{TEA}$,

DMSO, $22^{\circ} \mathrm{C}, 1 \mathrm{~h}$

$93 \%$

i) $8 \mathrm{M} \mathrm{MeNH}_{2}$ in $\mathrm{EtOH}, \mathrm{AcOH}$,

toluene: $\mathrm{EtOH}, 18-24^{\circ} \mathrm{C}, 54 \mathrm{~min}$.

ii) $\mathrm{NaBH}_{4}, \mathrm{AcOH}, \mathrm{THF}, 2^{\circ} \mathrm{C}, 13 \mathrm{~h}$

$92 \%$

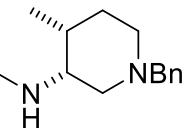

10

dr 86:14
$32 \% \mathrm{HCl}$, toluene/EtOH

$62 \%$

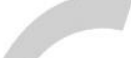


WILEY-VCH

Alternative starting materials were also disclosed by Pfizer (Scheme 3). ${ }^{[15],[14]}$ The first alternative (Scheme 3, a) starts with 3amino-4-methyl pyridine (11), which was protected to form the carbamate 12 followed by hydrogenation to yield (4-methylpiperidin-3-yl)-carbamic acid methyl ester (13) in a 5:1 (cis:trans) ratio. After $\mathrm{N}$-benzylation via reductive amination, reduction of cis(1-benzyl-4-methyl-piperidin-3-yl)-carbamic acid methyl ester using $\mathrm{LiAlH}_{4}$ and treatment with $\mathrm{HCl}$, the hydrochloride salt 4 was obtained. The patent does not describe the final cis:trans ratio. The same procedure was employed by Biocryst Pharmaceuticals to attain $\mathbf{4}$, which was resolved to compound 5 in $21 \%$ yield. ${ }^{[16]} \mathrm{A}$ similar method was also described comprising minor changes in the conditions used. ${ }^{[17]}$

A second alternative uses 4-methylpiperidine (14) to prepare the methyl 4-methyl-3-(methylamino)piperidine-1-carboxylate (19) (Scheme 3, b). The sequence comprised an electrochemical oxidation followed by a thermal elimination to obtain in situ compound 17. After the acetate cleavage to give the corresponding ketone, a reductive amination to insert the methylamine moiety yielded 19. This derivative could be envisaged as a promising piperidine fragment. However, the authors perceived that the conformational change in the six-membered ring resulted in a low selectivity in reductive amination.

a)

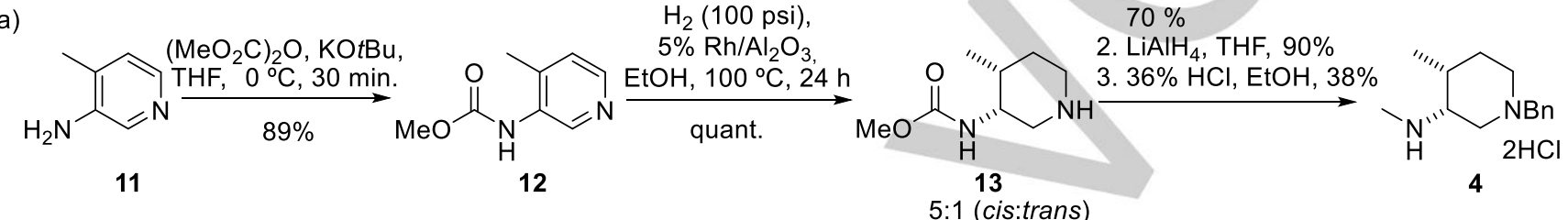

1. $\mathrm{PhCHO}, \mathrm{NaBH}(\mathrm{OAc})_{3}$, $\mathrm{DCM}, 20^{\circ} \mathrm{C}, 30 \mathrm{~min}$., $70 \%$

2. $\mathrm{LiAlH}_{4}, \mathrm{THF}, 90 \%$

b)

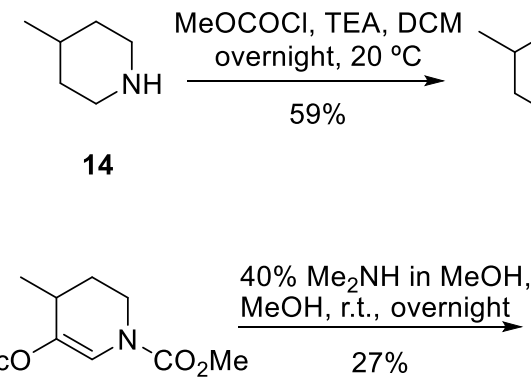

17

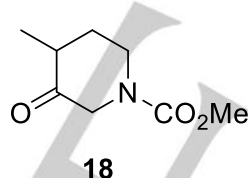

18

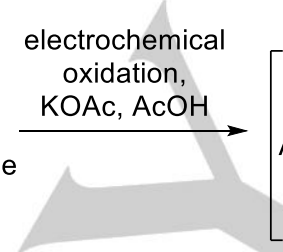

$5: 1$ (cis:trans)
$\mathrm{Ac}_{2} \mathrm{O}, 140^{\circ} \mathrm{C}, 2 \mathrm{~h}$

then r.t., overnight

$86 \%$
15

$2 \mathrm{M} \mathrm{MeNH}_{2}$ in $\mathrm{MeOH}$, $\mathrm{NaBH}_{4} \mathrm{AcOH}, \mathrm{EtOH}$<smiles>CNC1CCCN(C(=O)OC)C1</smiles>

19

Scheme 3. Pfizer's alternative approaches (2004) to obtain 4 and 19. ${ }^{[14],[15]}$

In 2007, Ruggeri et al. (Pfizer) disclose an alternative method to prepare intermediate $\mathbf{1 0}$ from compound 12 (Scheme 4). ${ }^{[18]}$ The patent comprises the benzylation of $\mathbf{1 2}$ to give the corresponding quaternized salts 20 and 21. Asymmetric hydrogenation of compound $\mathbf{2 0}$ was performed in the presence of a particular Rh catalyst/phosphine ligand system used to favour the cis enrichment. Thus, intermediate 10 was obtained with $84 \%$ of cis product $(68 \%$ ee). On the other hand, 21 was first reduced to methyl (1-benzyl-4methyl-1,2,5,6-tetrahydropyridin-3-yl) carbamate (22), followed by asymmetric hydrogenation under the same conditions yielding $\mathbf{1 0}$ with $97 \%$ of cis product $(66 \%$ ee).

Patil et al. also employed $\mathbf{1 1}$ as starting material to produce $\mathbf{5}$ in a "two-step process" with an overall yield of $26 \%$ (Scheme 5). ${ }^{[19]}$ The first step comprised the formation in situ of the $\mathrm{N}$-acylated intermediate 25. Despite the resemblance to the carbamate derivatives 22 described on the previous method, the alternative $N$ - acylation of 11 seems to influence the reaction sequence efficiency, since 25 was obtained in $82 \%$ in high purity $(95 \%$, assessed by HPLC) without requiring the intermediates isolation. Intermediate $\mathbf{2 5}$ was further converted in situ into compound $\mathbf{5}$, by acid treatment to give $\mathbf{2}$ followed by reductive amination with sodium borohydride in the presence of titanium (IV) tetraisopropoxide (TTIP). The authors also elucidate the formation of the four stereoisomers of $\mathbf{1 0}$, observing that 1,3-diaxial interactions hinder the formation of trans isomers. Resolution with L-DTTA produced the desired compound 5 in $37 \%$ yield ( $98.6 \%$ ee, assessed by chiral GC). The process presents some advantages, such as the absence of expensive metal catalysts, not requiring the isolation of four intermediates without influencing the required API purity. Rao and Zhang also reported a similar sequence involving the protection of $\mathbf{1 1}$ with Boc, however without mentioning the corresponding ee. ${ }^{[20]}$ 


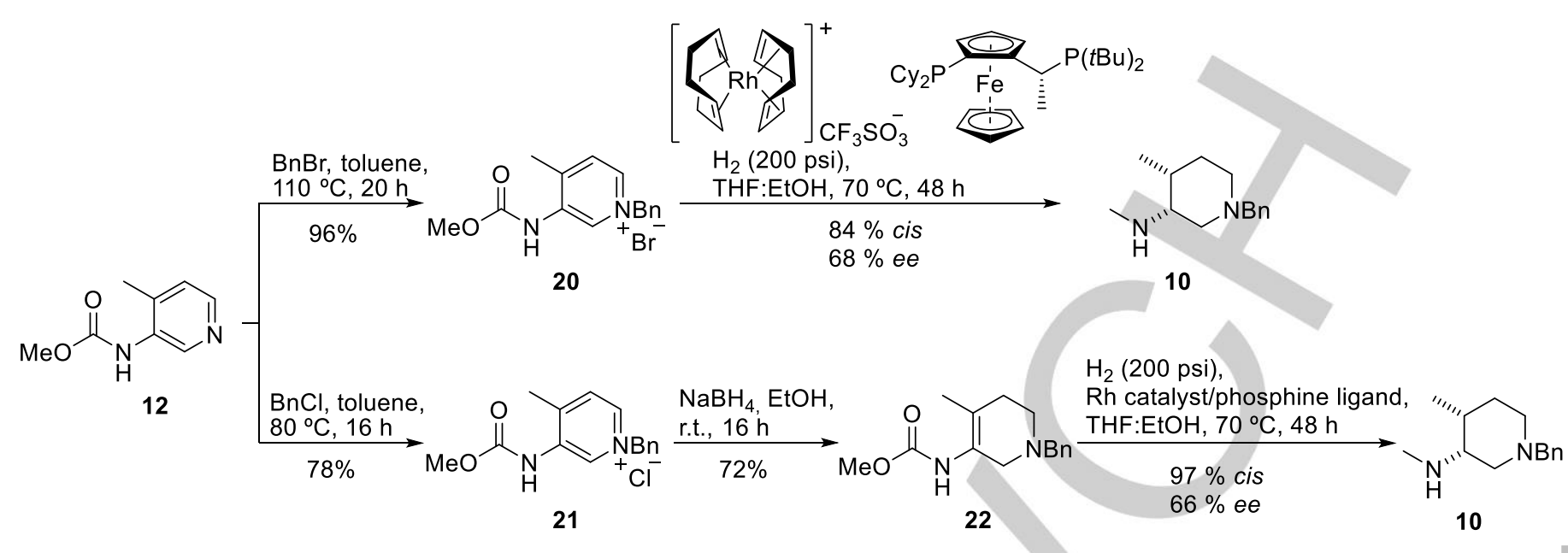

Scheme 4. Pfizer's approach (2007) to produce compound 10 from 12. ${ }^{[18]}$

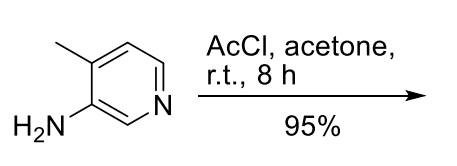

11

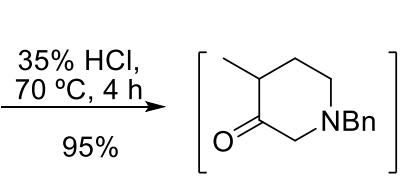

2<smiles>CC(=O)Nc1cnccc1C</smiles>

23

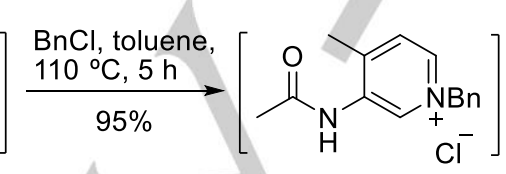

24

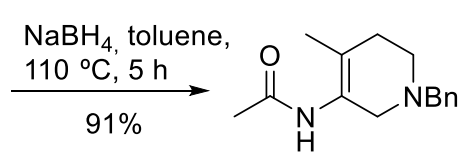

25

i) $\mathrm{Ti}(\mathrm{O} i \mathrm{Pr})_{4}, 33 \% \mathrm{MeNH}_{2}$ in

$\mathrm{MeOH}, 15^{\circ} \mathrm{C}, 1 \mathrm{~h}$

ii) $\mathrm{NaBH}_{4}, \mathrm{MeOH}$, r.t., $3 \mathrm{~h}$

$96 \%$

$(R, R) 50.2 \%$

(S,S) $43.90 \%$

trans $5.86 \%$

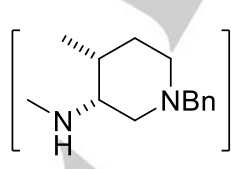

10
di-p-toluoyl-L-tartaric acid, $\underset{40 \%}{\mathrm{MeOH} / \mathrm{H}_{2} \mathrm{O}, 1 \mathrm{~h}}$

$(R, R) 98.6 \%$

$(S, S) 0.16 \%$

trans $1.19 \%$

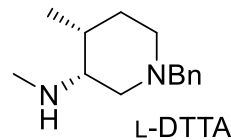

5

Scheme 5. Patil's "two-step process" to produce compound 5 from 11. ${ }^{[19]}$

Hashmi et al. (Ranbaxy Laboratories Ltd) disclosed a procedure involving the bromination of 4-methylpyridine 7, followed by quaternization, a copper-catalysed amination of intermediate 27 and a final reductive step to attain 10 (Scheme 6). ${ }^{\left[{ }^{11]}\right.}$ However, the authors do not provide any information about the ee or drobtained. In 2014, Stavber and Cluzeau (Lek Pharmaceuticals) disclose several alternative approaches to attain 10 (Scheme 7). ${ }^{[22]}$ Within the methods described, 10 could be obtained from compound 8 by direct amination to attain 29 followed by dehydration to give the corresponding endo and exo compounds 30 . The reduction was tested using different conditions, being observed the best cis:trans ratio (1.9:1) using the $\mathrm{Rh} / \mathrm{C}$ catalyst.
$\mathrm{Cu}_{2} \mathrm{O}$

$11.5 \% \mathrm{MeNH}_{2}$ in $\mathrm{MeOH}$

$\mathrm{BnBr}$, toluene<smiles>Cc1ccncc1</smiles>

i) $\mathrm{AlCl}_{3}, 1 \mathrm{~h}$

ii) $\mathrm{Br}_{2}, 105^{\circ} \mathrm{C}, 35 \mathrm{~h}$

7

26 $110^{\circ} \mathrm{C}, 20 \mathrm{~h}$

$87 \%$

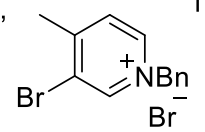

27

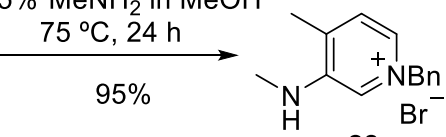

28
$\mathrm{NaBH}_{4}$, $\mathrm{EtOH} / \mathrm{H}_{2} \mathrm{O}$, $\underset{54 \%}{\stackrel{\text { r.t., } 20 \mathrm{~h}}{\longrightarrow}}$ 10

Scheme 6. Hashmidi's procedure involving the bromination of 7 and a copper-catalysed amination to produce $10 .{ }^{[21]}$ 


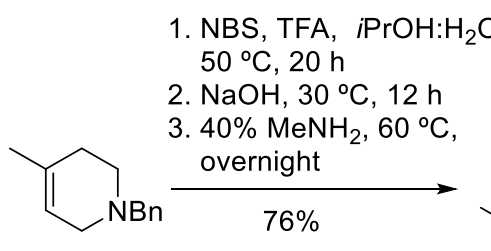

8<smiles>CNC1CN(Cc2ccccc2)CCC1(C)O</smiles>

29

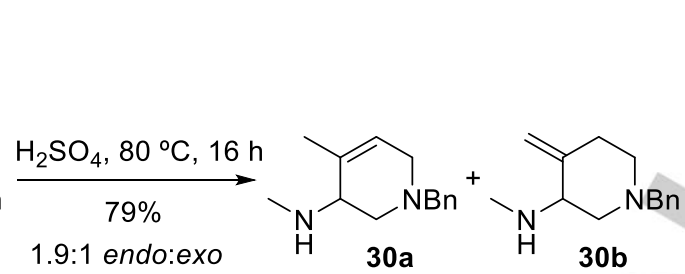

$30 \mathrm{a}$
$\mathrm{H}_{2}$ (20 atm), $5 \% \mathrm{Rh} / \mathrm{C}$,

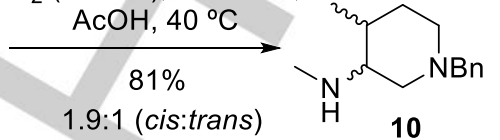

Scheme 7. One of the approaches disclosed by Stavber and Cluzeau to obtain 10. ${ }^{[22]}$

Very recently, it was reported the asymmetric synthesis of $\mathbf{1 0}$ from chiral 1,3-dioxolanone (31) (Scheme 8). ${ }^{[23]}$ The work takes advantage of preliminary studies, in which the authors report the preparation of $\mathbf{3 1}$ via a stereoselective Michael addition of the corresponding enolate of chiral 1,3-dioxolanone to methyl crotonate with high diastereoselectivity $(d r>99: 1)$. Removal of the chiral auxiliary and formation of the corresponding diamide intermediate $\mathbf{3 2}$ was achieved in high yield under neat conditions, followed by lactonization to yield 33. Ring expansion was performed in the presence of lithium diisopropylamide (LDA) and molecular sieves to form $\mathbf{3 4}$, requiring the dilution of the reaction mixture to improve the yield. To obtain the correct stereochemistry on the final compound, $\mathbf{3 5}$ had to be oxidized to piperidone $\mathbf{3 6}$, which was performed by Jones oxidation. Since $\mathbf{3 6}$ was unstable, the compound was used directly on the reductive amination to attain 10 in 54\%. This asymmetric approach enables the preparation of $\mathbf{1 0}$ in a 4:1 cis:trans ratio without the need of chiral resolution.

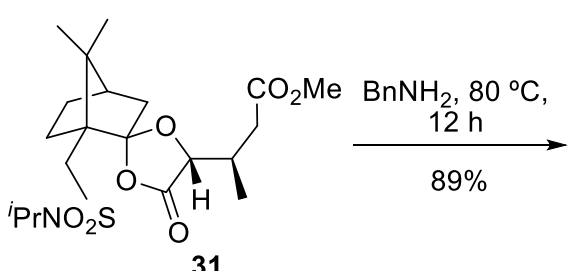

31

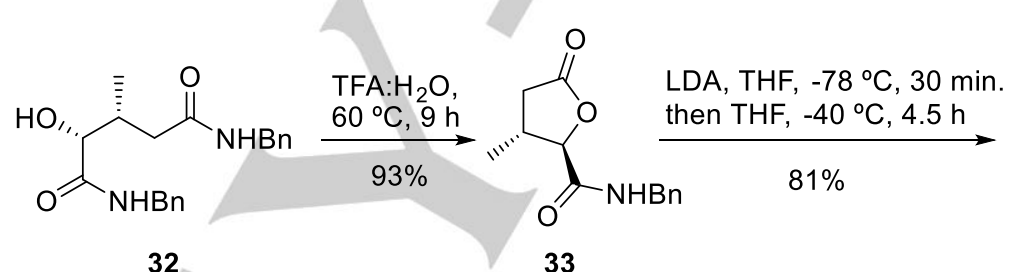

32<smiles>C[C@H]1CC(=O)N(Cc2ccccc2)C(=O)[C@@H]1O</smiles>

34
$\mathrm{CrO}_{3}, \mathrm{H}_{2} \mathrm{SO}_{4}, \mathrm{HOAc}$,

$\mathrm{LiAlH}_{4}, \mathrm{THF}$, $\stackrel{0^{\circ} \mathrm{C} \text { to } \mathrm{rfx}, 12 \mathrm{~h}}{\longrightarrow}$ $74 \%$

$$
\text { acetone } \mathrm{H}_{2} \mathrm{O}, 0^{\circ} \mathrm{C} \text { to r.t. }
$$
$\left(<18^{\circ} \mathrm{C}\right), 2 \mathrm{~h}$

35
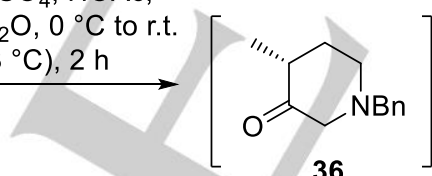

36

then $\mathrm{MeNH}_{2}(33 \%$ in $\mathrm{EtOH})$, $\mathrm{HOAc}, \mathrm{NaBH}(\mathrm{OAc})_{3}$,

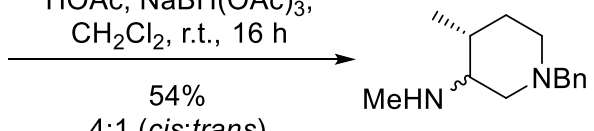

$4: 1$ (cis:trans)

10

Scheme 8. Liao's asymmetric approach to attain $10 .^{[23]}$

Other piperidine analogues were also described. In a long synthetic approach involving eight steps, Jiang et al. describe the preparation of fragment 10 from L-serine (37) (Scheme 9). ${ }^{[24]}$ This approach was inspired by a previous report, which employed D-serine to obtain several (3S)-amino piperidine derivatives. ${ }^{[25]}$ The main aim of Jiang's work was the development of various enantiopure stereoisomers, where the stereocenter at $\mathrm{C} 3$ of the piperidine ring is established by the choice of the serine derivative. The strategy involved the preparation of tert-butyl $(R)$-(1-(allyl(benzyl)amino)-3methylbut-3-en-2-yl)carbamate (42), followed by a ring-closing metathesis reaction using Grubbs II catalyst to deliver the piperidine derivative $\mathbf{4 3}$. Subsequent hydrogenation resulted in a mixture of compounds 44, which were chromatographically separated. The authors also used D-serine as starting material to produce the corresponding stereoisomers. Reduction of $44 \mathrm{~b}$ with $\mathrm{LiAlH}_{4}$ yielded the desired compound 10. ${ }^{[14]}$

An alternative method employs L-malic acid (45) as the chiral pool starting material, to attain the Cbz-protected compound 52 (Scheme 10).[26] Despite the extensive synthetic sequence (16 steps), the authors claim that the synthetic sequence possessed several advantages, such as cheap raw materials, mild reaction conditions and an overall yield of $26 \%$ yielding the product $\mathbf{5 4}$ with $>98 \%$ ee. 


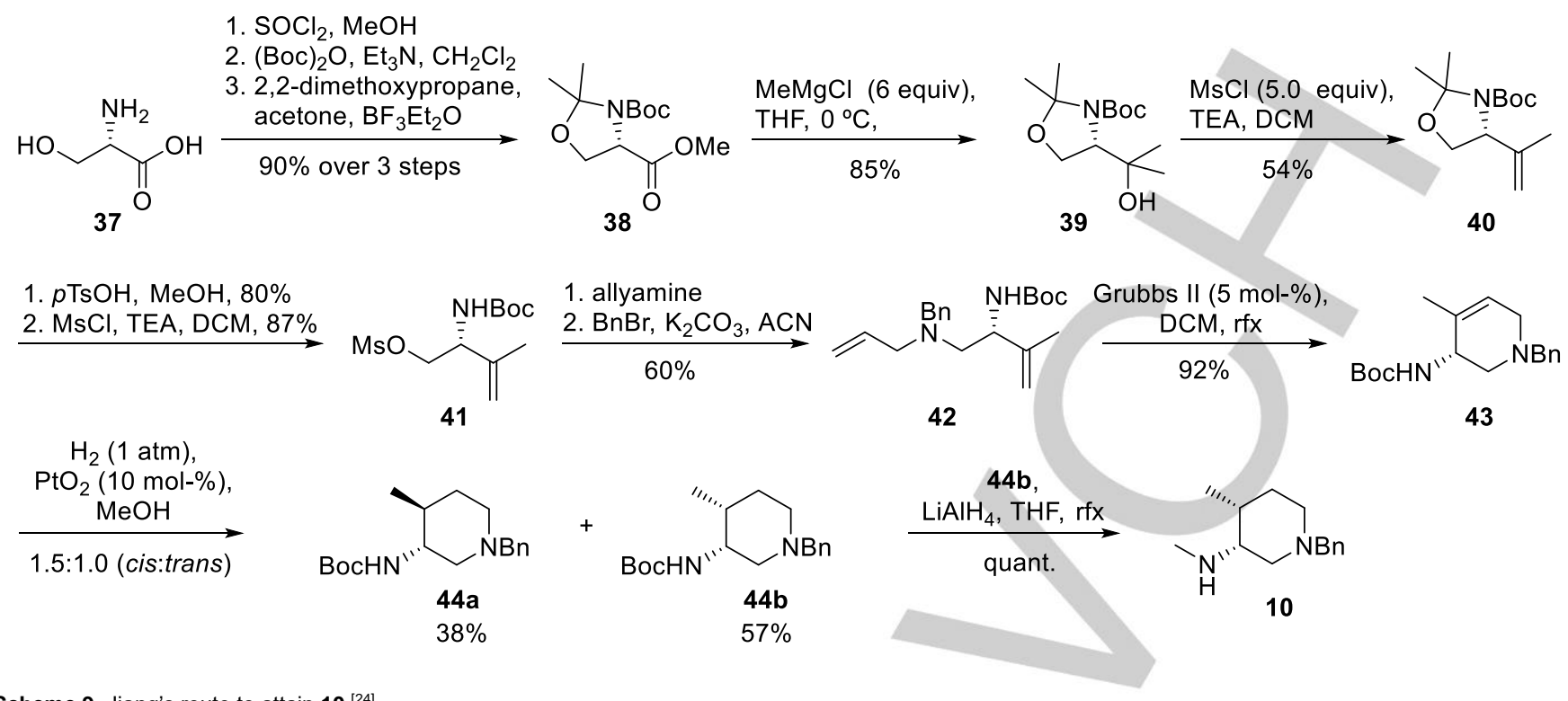

Scheme 9. Jiang's route to attain $10 .{ }^{[24]}$
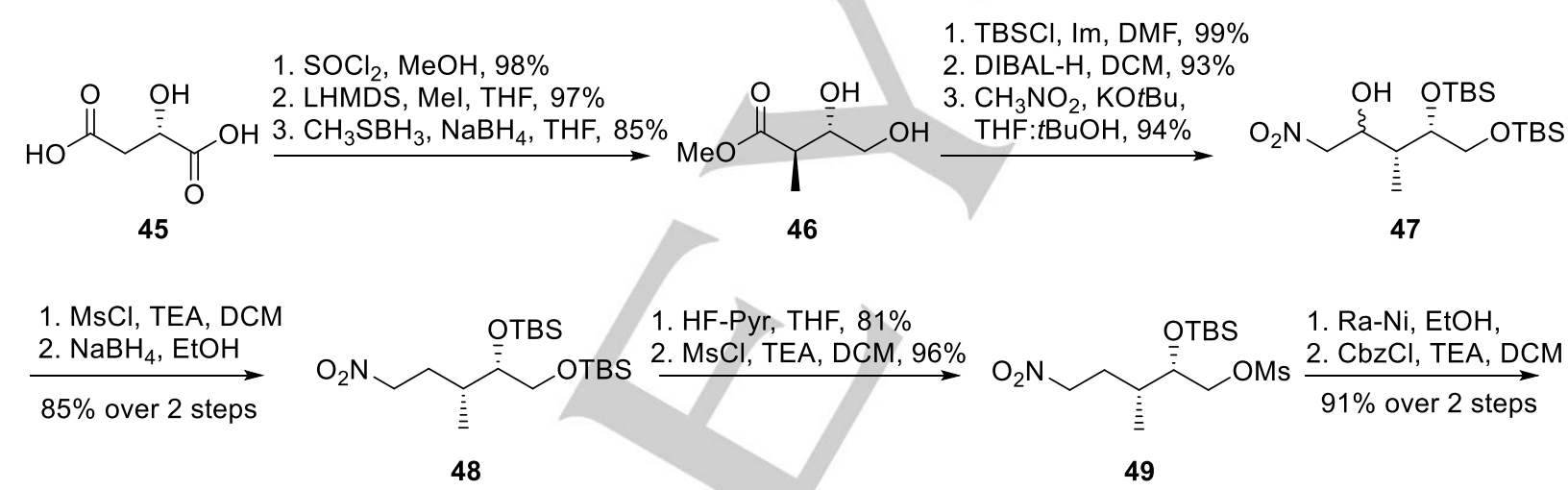

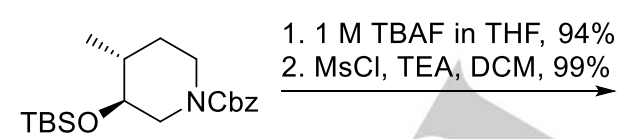

50

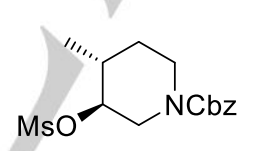

51

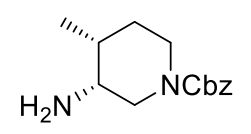

52

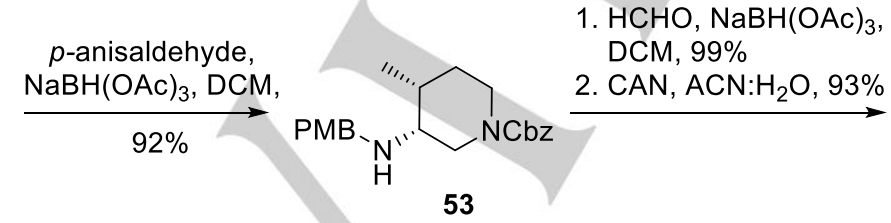

53
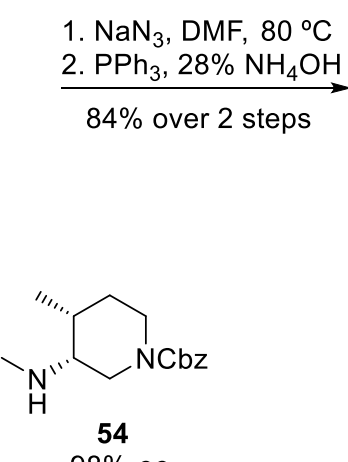

Scheme 10. Hao's route using L-malic acid (45) as starting material. ${ }^{[26]}$

In 2011, the same group reported the preparation of a Bocprotected piperidine 62 from the commercially available ethyl 1benzyl-3-oxopiperidine-4-carboxylate hydrochloride (55) (Scheme 11). ${ }^{[27]}$ The first step comprised the replacement of benzyl by a Boc protection, preventing concurrent deprotection in a later step. It was then envisaged that the introduction of an auxiliary $(R)-\alpha-$ methylbenzylamino group, could induce the desired final configuration. After screening different metal catalysts for the asymmetric reduction, $\mathbf{5 5}$ was obtained in good diastereomeric excess using $\mathrm{NaBH}(\mathrm{OAc})_{3}$ in the presence of cobalt(II) chloride 


\section{MICROREVIEW}

$\left(\mathrm{CoCl}_{2}\right)$ and (S)-(-)-2,2'-p-tolyl-phosphino)-1,1'-binaphthyl [(S)TolBINAP] as the catalytic system. Methylation of amine by reductive amination followed by the ester reduction yielded compound 59. Intermediate $\mathbf{6 1}$ was obtained through a Mitsunobu reaction followed by a Raney Ni catalysed hydrogenation. Removal of the auxiliary group was performed using ammonium formate as the hydrogen source to give compound 62 in quantitative yield. The latter was obtained in an overall yield of $49 \%$ and although stated that it was obtained in high enantiomeric excess, the value is not described.

In 2014, the preparation of a trityl-protected derivative from compound $\mathbf{1 1}$ was disclosed, ${ }^{[28]}$ benefiting from the already described approach (see Scheme 3).
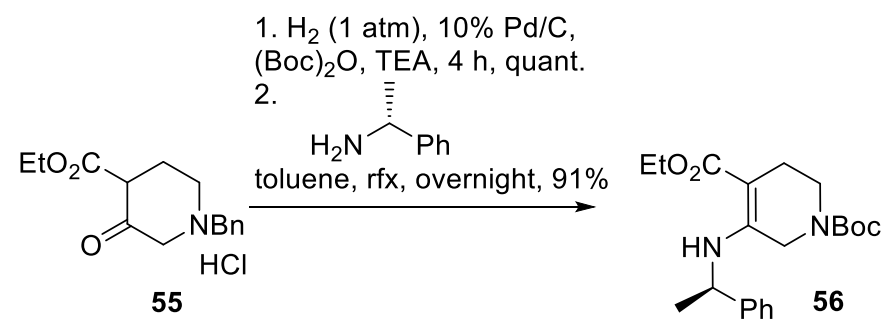

i) $\mathrm{CoCl}_{2} .6 \mathrm{H}_{2} \mathrm{O}(1 \mathrm{~mol}-\%)$

(S)-TolBINAP,

DCM:DMF, r.t., $1 \mathrm{~h}$

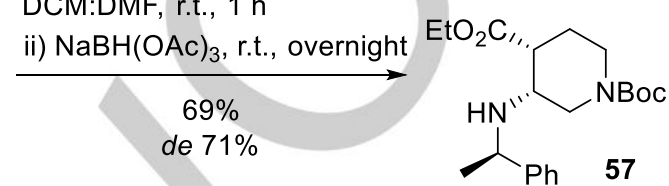

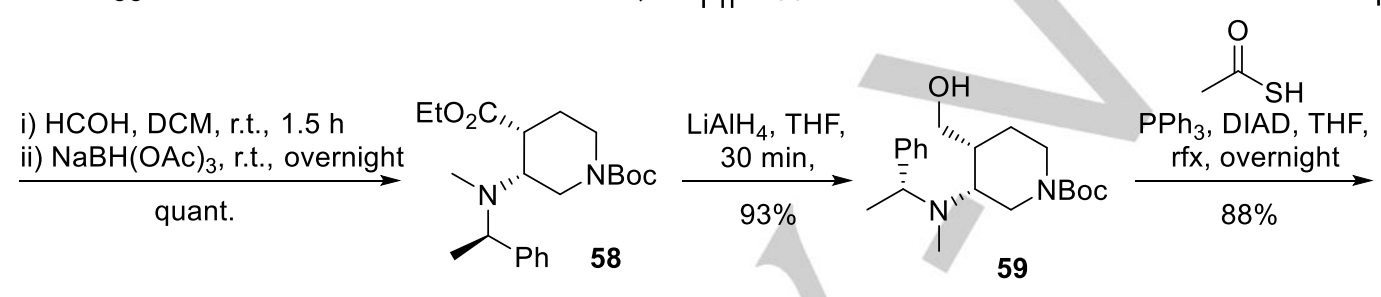<smiles>C[C@@H]1CCN(S(=O)(=O)OCc2ccccc2)C[C@@H]1N(C)[C@H](C)c1ccccc1</smiles>

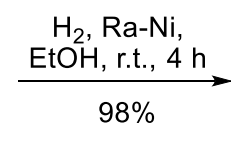

60

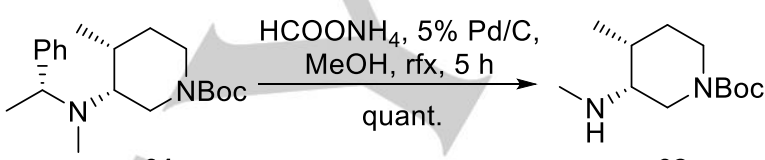

62

Scheme 11. Hao's route using 55 as starting material. ${ }^{[27]}$

It is interesting to mention that preparation of 3-((3R,4R)-4-methyl3-(methylamino)piperidin-1-yl)-3-oxopropanenitrile or its hydrochloride salt (65) is also described and used to prepare tofacitinib-related structures. Babu et al. (Biocryt Pharmaceuticals Inc.) describe its preparation from compound 5 (Scheme 12). ${ }^{[16]}$ Moreover, Gehringer et al. used a similar strategy in order to prepare alternative tofacitinib bioisosteres. Compound 65 was employed since some substrates were incompatible with the usual hydrogenation conditions used to cleave the benzyl group. However, it is also stated that derivative $\mathbf{6 5}$ is not stable under some conditions. ${ }^{[29]}$

Other alternative approaches were described to attain several tofacitinib structures with different deuterated patterns (Scheme 13). ${ }^{[20]}$

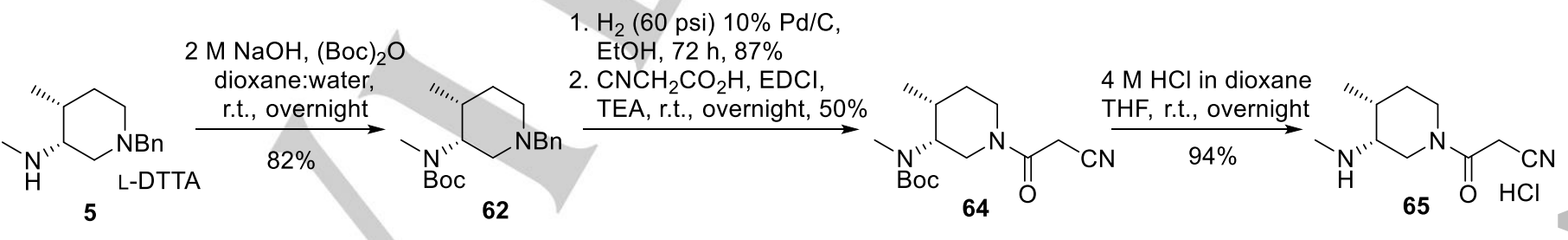

Scheme 12. Babu's approach to attain compound $65 .^{[16]}$ 


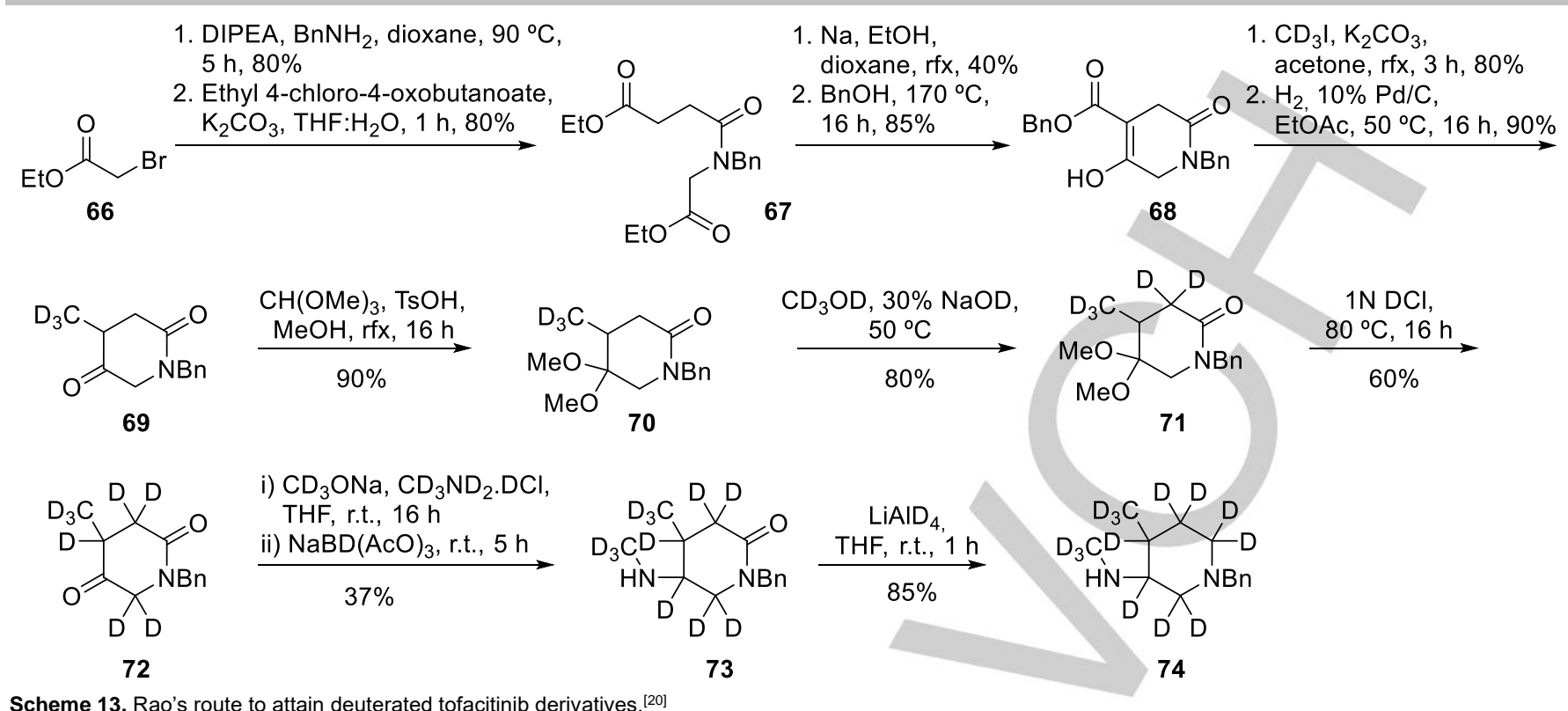

Scheme 13. Rao's route to attain deuterated tofacitinib derivatives. ${ }^{[20]}$

An alternative strategy to attain 1 involving a Mitsunobu reaction, conducted to the development of a novel piperidine analogue (Scheme 14). ${ }^{[30]}$ In 2013, Maricán et al. reported the preparation of tert-butyl-(3S,4R)-3-hydroxy-4-methyl piperidine-1-carboxylate (81), a key synthetic intermediate obtained in 6 steps from compound 75. ${ }^{[31]}$ Preliminary TBDPS and Boc protections followed by a selenoxide elimination yielded 78 . Compound 79 was obtained with a de $>94 \%$ via a Grignard methyl cuprate addition. Reduction followed by silyl group deprotection afforded $\mathbf{8 1}$ with an overall yield of $18 \%$

Alternatively, compound $\mathbf{8 1}$ was obtained from crotyl alcohol via an eight-step synthetic sequence with a yield of $19 \%(98 \%$ ee $) .{ }^{[32]}$

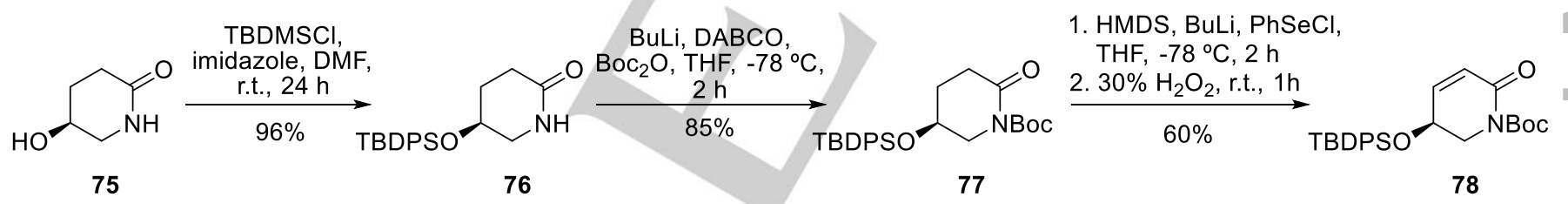

$\mathrm{MeMgBr}, \mathrm{CuBr} . \mathrm{SMe}_{2}$ $\mathrm{TMSCl}, \mathrm{Et}_{2} \mathrm{O}$, $-20^{\circ} \mathrm{C}, 2 \mathrm{~h}$

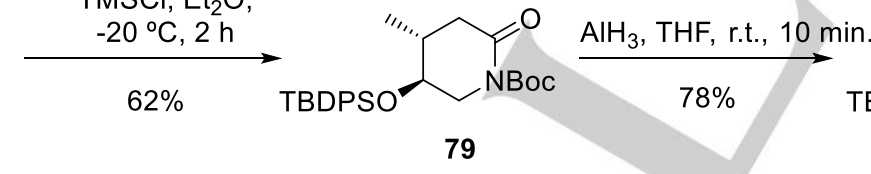

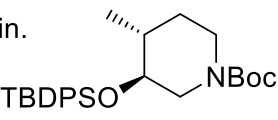

80

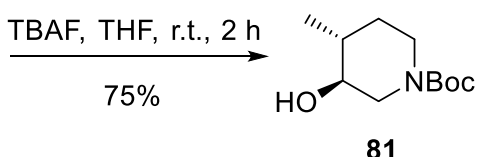

81

Scheme 14. Maricán's approach to produce the alternative intermediate $81 .^{[30]}$

\section{Tofacitinib assembly}

As already mentioned, the retrosynthetic analysis performed for tofacitinib (1) can assume two major fragments: the pyrrolo[2,3d]pyrimidine moiety and a chiral 3,4-disubstituted piperidine ring. Following this idea, the most notorious disconnection can be performed either: 1) between the pyrrolo pyrimidine ring and the 3amino-4-methyl piperidine moiety or 2) between the 4-amino- pyrrolo[2,3-d]pyrimidine structure and the piperidine ring (Scheme 15). In fact, the first reported synthesis of $\mathbf{1}$, comprised a $S_{N} A r$ reaction of 3 with 4-chloro-pyrrolo[2,3-d]pyrimidine (82), also known by 6 -chloro-7-deazapurine), followed by hydrogenation to cleave the benzyl group and a final cyanoacetic side-chain insertion involving several approaches (Scheme 16). ${ }^{[4]}$ Due to the easy and cheap production of $\mathbf{8 2}$ and the convenient benzyl protection of the piperidine ring, this simple synthetic sequence was rapidly adopted and has been generally employed in most of the subsequent reports. 


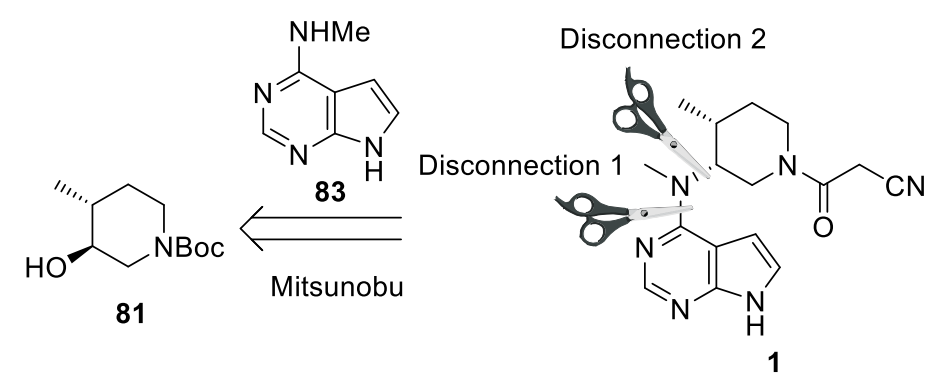

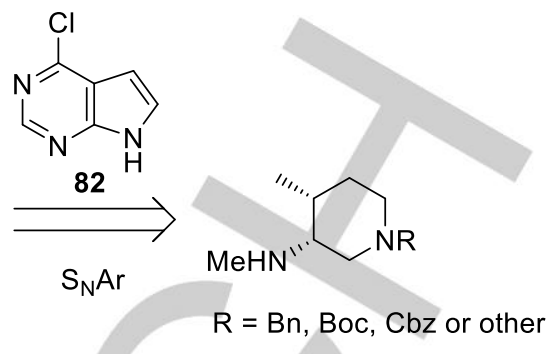

Scheme 15. Common tofacitinib disconnections.

The synthetic sequence to attain tofacitinib (1) usually starts by preparing 82 from the cheapest 7-deazahypoxanthine (CAS 3680-71-5) in good yields, ${ }^{[3]}$ although it can be currently purchased from different sources. Compound 82 can also be prepared from smaller fragments but with a longer synthetic sequence. ${ }^{16]}$ The nucleophilic substitution of chlorine with $\mathbf{3}$ (or one of its salts) was normally performed at reflux temperature employing different conditions, such as $\mathrm{K}_{2} \mathrm{CO}_{3}$ in water, ${ }^{[4],[16]}$ $\mathrm{Na}_{2} \mathrm{CO}_{3}$ in water (sealed tube), ${ }^{[29]}$ or neat in TEA, ${ }^{[34]}$ usually with low yields. Alternatively, compound $\mathbf{8 6}$ can also be used in the $\mathrm{S}_{N} \mathrm{Ar}$ showing better yields than the obtained with $82 .{ }^{[18]}$ Chloride displacement occurs under the hydrogenation conditions yielding 85 .
In order to enhance the reaction yield and reduce undesired impurities, several groups employed a tosyl-protection for intermediate 8 88. $^{[18],[24],[19],[23]}$ Indeed, heating the tosylated 88 with 5 in water in the presence of $\mathrm{K}_{2} \mathrm{CO}_{3}$, yielded 89 in $85 \%$ (Scheme 17). ${ }^{[19]}$ This protection-deprotection methodology does not have a detrimental effect on yield, which may be higher than the observed for direct substitution with the piperidine intermediate. Detosylation can be simply performed using a $\mathrm{NaOH}$ aqueous solution. ${ }^{[18]}$ However, it was observed that water could promote undesired racemization, which could be prevented by using methanol. ${ }^{[19]}$

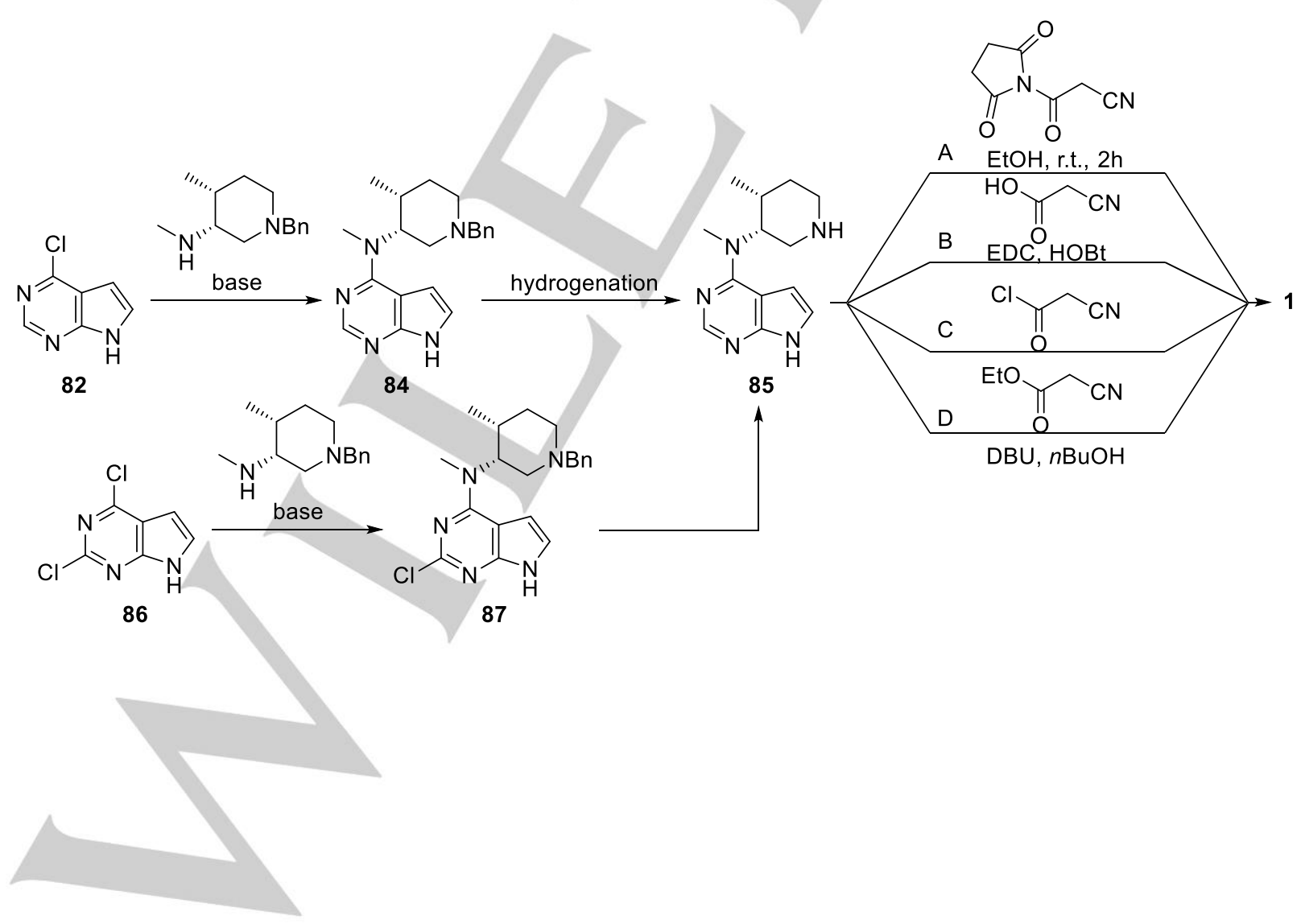




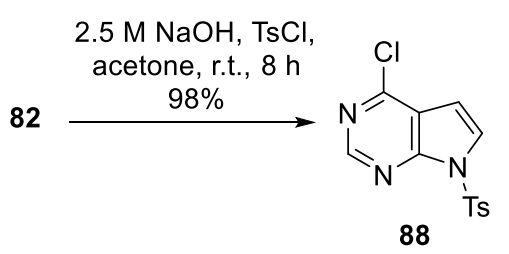

88

Scheme 17. Use of tosylated derivative 88 to attain intermediate $84 .^{[19]}$

Debenzylation of $\mathbf{8 4}$ was performed under standard conditions. The original hydrogenation conditions used $20 \% \mathrm{Pd} / \mathrm{C}$ in ethanol in the presence of $\mathrm{HCl}^{\left[{ }^{[4]}\right.}$ Other conditions employed $20 \% \mathrm{Pd}(\mathrm{OH})_{2} / \mathrm{C}$ in $\mathrm{H}_{2} \mathrm{O} / \mathrm{PrOH} / \mathrm{AcOH}$ or in $\mathrm{MeOH} / \mathrm{TFA}$, or a combined $20 \% \mathrm{Pd}(\mathrm{OH})_{2} / \mathrm{C}-$ $10 \% \mathrm{Pd} / \mathrm{C}$ system in $\mathrm{MeOH} .{ }^{[29]}$ The reaction can be performed at room temperature, although the reaction times could be significantly decreased employing higher temperatures.

Installation of the cyanoacetate chain was the transformation that showed more diversity in the employed procedures. The first described method employed cyanoacetic acid pyrrolidin-1-yl ester in ethanol (Scheme 16, A). ${ }^{[4],[34]}$ However, most of the procedures rely on the cyanoacetic acid activation employing a proper activating agent. Thus different systems were used: HATU/ $\mathrm{Pr}_{2} \mathrm{NEt}$, ${ }^{[24]} \mathrm{TBTU} / \mathrm{HOBt} / \mathrm{DIPEA}$ or EDC/HOBt ${ }^{[30]}$ (Scheme 16, B). ${ }^{[29]}$ Alternatively, 1 could be obtained from the corresponding acid chloride (Scheme 16, C) or refluxing ethyl cyanoacetate in the presence of TEA in toluene (65\%). ${ }^{[18]}$ Price et al. also report a protocol for direct amidation of alkyl cyanoacetates using 1,8diazabicyclo[5.4.0]undec-7-ene (DBU) in 1-BuOH. The authors described a single-step process which does not require a preliminary acid activation, avoiding the decomposition of the activated acid and reduction of waste, being a good solution for large-scale production. Tofacitinib (1) was obtained (as the citric acid salt) using 0.5 equiv of DBU within $12 \mathrm{~h}$ at $40{ }^{\circ} \mathrm{C}(90 \%)$ (Scheme 16, D). ${ }^{[35]}$

An alternative coupling of piperidine functionality to the heterocyclic moiety was devised from a different retrosynthetic point-of-view. The authors report a reaction sequence involving a Mitsunobu reaction between the tert-butyl-(3S,4R)-3-hydroxy-4-methylpiperidine-1-carboxylate (81) and 90 (Scheme 18). ${ }^{[30]}$ The latter was prepared from the corresponding 6-amino-7-deazapurine (83) via reductive amination using a $\mathrm{HCHO} / \mathrm{NaBH}_{3} \mathrm{CN}$ system. Application of the standard Mitsunobu conditions $\left(\mathrm{Ph}_{3} \mathrm{P} / \mathrm{DIAD}\right)$, yielded 91 in $68 \%$ yield $(>94 \%$ de). It is worthy to mention, that on the opposition to the trendy benzyl-protected piperidine fragment, herein the authors presented a Boc-protection, which was cleaved using $\mathrm{ZnBr}_{2}$ to yield 85. Coupling of the resulting amine with cyanoacetic acid through an EDC/HOBt activation afforded $\mathbf{1}$ in $80 \%$ yield. The overall yield $(9.5 \%)$, which includes the preparation of 81 (see Scheme 14), overcomes some of the previous methodologies.

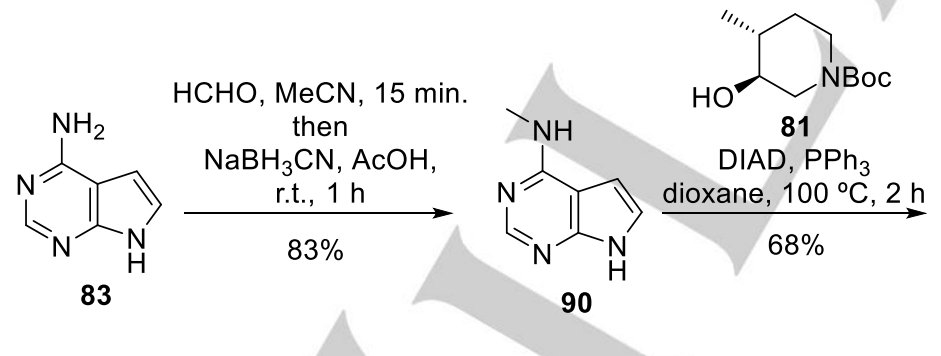

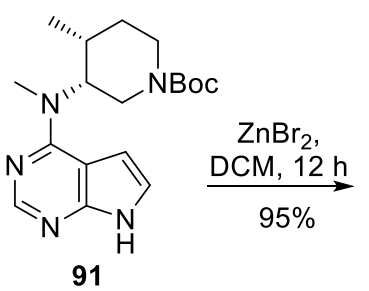<smiles>C[C@@H]1CCNC[C@H]1N(C)c1ncnc2[nH]ccc12</smiles><smiles>N#CCC(=O)OCc1ccccc1</smiles>
$80 \%$
1 (1)

Scheme 18. Preparation of tofacitinib via Mitsunobu approach. ${ }^{[30]}$

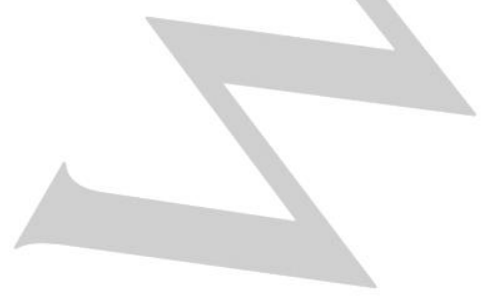




\section{Conclusions}

This review describes the continuous improvements performed on tofacitinib synthesis, particularly on the intricate preparation of a key structural feature fundamental to its activity. These synthetic efforts indicate the growing importance of this API in different therapies and how it is still extensively studied towards several pathologies. Moreover, the implementation of convenient synthetic strategies in industry is still highly demanding, with permanent scouting for efficient and cost-effective solutions without forgetting the safety and environmental protection. The review covers the literature since the initial attempts to prepare this important structure until the recent trends, observing the large efforts performed to fulfil these demands. It collects valuable information from the different methods and expects to motivate other groups to pursue this challenging endeavor.

\section{Acknowledgements}

This work was supported by the Associated Laboratory for Sustainable Chemistry - Clean Processes and Technologies $L A Q V$, which is financed by national funds from FCT/MEC(UID/QUI/50006/2013 and co-financed by the ERDF under the PT2020 Partnership Agreement (POCI-01-0145FEDER-007265). The authors would like to thank Hovione FarmaCiencia SA for financial support.

Keywords: asymmetric synthesis $\cdot$ chiral resolution $\cdot$ nitrogen heterocycles $\cdot$ piperidine ring $\bullet$ tofacitinib

[1] J. J. Babon, I. S. Lucet, J. M. Murphy, N. A. Nicola, L. N. Varghese, Biochem. J. 2014, 462, 1-13.

[2] D. M. Schwartz, M. Bonelli, M. Gadina, J. J. O'Shea, Nat. Rev. Rheumatol. 2016, 12, 25-36.

[3] S. M. Russell, N. Tayebi, H. Nakajima, M. C. Riedy, J. L. Roberts, M. J. Aman, T. S. Migone, M. Noguchi, M. L. Markert, R. H. Buckley, J. J. O'Shea, W. J. Leonard, Science 1995, 270, 797-800.

[4] G. Wilcox, C. Koecher, T. Vries, M. E. Flanagan, M. J. Munchhof, WO/2002/096909, 2002.

[5] M. E. Flanagan, M. F. Brown, C. Subramanyam, M. J. Munchhof in Annual Reports in Medicinal Chemistry, Vol. 49, (Ed.: M. C. Desai), Academic Press, Amsterdam, 2014, pp. 399-416.

[6] P. S. Changelian, M. E. Flanagan, D. J. Ball, C. R. Kent, K. S. Magnuson, W. H. Martin, B. J. Rizzuti, P. S. Sawyer, B. D. Perry, W. H. Brissette, S. P. Mccurdy, E. M. Kudlacz, M. J. Conklyn, E. A. Elliott, E. R. Koslov, M. B. Fisher, T. J. Strelevitz, K. Yoon, D. A. Whipple, J. Sun, M. J. Munchhof J. L. Doty, J. M. Casavant, T. A. Blumenkopf, M. Hines, M. F. Brown, B. M. Lillie, C. Subramanyam, C. Shang-poa, A. J. Milici, G. E. Beckius, J. D. Moyer, C. Su, T. G. Woodworth, A. S. Gaweco, C. R. Beals, B. H. Littman, D. A. Fisher, J. F. Smith, P. Zagouras, H. A. Magna, M. J.
Saltarelli, K. S. Johnson, L. F. Nelms, S. G. Des Etages, L. S. Hayes, T. T. Kawabata, D. Finco-kent, D. L. Baker, M. Larson, M. Si, R. Paniagua, J. Higgins, B. Holm, B. Reitz, Y. Zhou, R. E. Morris, J. J. O. Shea, D. C. Borie, Science 2003, 302, 875-878.

[7] G. Thoma, P. Drückes, H. Zerwes, Bioorg. Med. Chem. Lett. 2014, 24, 4617-4621.

[8] C. Haan, C. Rolvering, F. Raulf, M. Kapp, P. Drückes, G. Thoma, I. Behrmann, H. G. Zerwes, Chem. Biol. 2011, 18, 314-323.

[9] L. C. S. De Vries, M. E. Wildenberg, W. J. De Jonge, G. R. D'Haens, J. Crohn's Colitis 2017, 11, 885-893.

[10] M. S. Zand, Transplant. Rev. (Copenhagen, Den.) 2013, 27, 85-89.

[11] T. Blumenkopf, M. Flanagan, M. Munchhof, WO/2001/42246, 2001

[12] M. A. Iorio, P. Ciuffa, G. Damia, Tetrahedron 1970, 26, 5519-5527.

[13] D. H. B. Ripin, S. Abele, W. Cai, T. Blumenkopf, J. M. Casavant, J. L. Doty, M. Flanagan, C. Koecher, K. W. Laue, K. Mccarthy, C. Meltz, M. Munchhoff, K. Pouwer, B. Shah, J. Sun, J. Teixeira, T. Vries, D. A. Whipple, G. Wilcox, Org. Process Res. Dev. 2003, 7, 2169-2172.

[14] W. Cai, J. L. Colony, H. Frost, J. P. Hudspeth, P. M. Kendall, A. M. Krishnan, T. Makowski, D. J. Mazur, J. Phillips, D. H. Brown Ripin, S. G. Ruggeri, J. F. Stearns, T. D. White, Org. Process Res. Dev. 2005, 9, 51 56.

[15] D. H. B. Ripin, WO/2004/046112, 2004

[16] Y. Babu, P. Chand, P. Kotian, V. Kumar, WO/2010/014930, 2010.

[17] S. Zhi, D. Liu, Y. Liu, B. Liu, D. Wang, L. Chen, J. Heterocycl. Chem. 2016, 53, 1459-1463.

[18] S. G. Ruggeri, J. Hawkins, T. Makowski, J. Rutherford, F. Urban, WO/2007/012953, 2007

[19] Y. S. Patil, N. L. Bonde, A. S. Kekan, D. G. Sathe, A. Das, Org. Process Res. Dev. 2014, 18, 1714-1720.

[20] T. Rao, C. Zhang, WO/2010/123919, 2010.

[21] M. Hashmi, Y. Sachdeva, C. Khanduri, WO/2014/097150, 2014.

[22] G. Stavber, J. Cluzeau, WO/2014/016338, 2014

[23] H. C. Liao, B. J. Uang, Tetrahedron: Asymmetry 2017, 28, 105-109.

[24] J. Jiang, K. Ghoreschi, F. Deflorian, Z. Chen, M. Perreira, M. Pesu, J. Smith, D. Nguyen, E. H. Liu, W. Leister, S. Costanzi, J. J. O. Shea, C. J. Thomas, J. Med. Chem. 2008, 51, 8012-8018.

[25] X. E. Hu, N. K. Kim, B. Ledoussal, Org. Lett. 2002, 1994-1997.

[26] B.-Y. Hao, J.-Q. Liu, W.-H. Zhang, X.-Z. Chen, Bull. Korean Chem. Soc 2013, 34, 1371-1377.

[27] B.-Y. Hao, J.-Q. Liu, W.-H. Zhang, X.-Z. Chen, Synthesis 2011, 8, 1208 1212.

[28] S. Bhirud, S. Mishra, S. Narayanan, S. Naykodi, A. Pardeshi, A. Dhiman S. Naik, WO/2014/102826, 2014

[29] M. Gehringer, M. Forster, E. Pfaffenrot, S. M. Bauer, S. A. Laufer ChemMedChem 2014, 2516-2527.

[30] A. Maricán, M. J. Simirgiotis, L. S. Santos, Tetrahedron Lett. 2013, 54 5096-5098.

[31] C. Herdeis, Synthesis 1986, 232-233.

[32] R. B. Kamble, G. Suryavanshi, Synth. Commun. 2018, 48, 1045-1051.

[33] J. Davoll, J. Chem. Soc. 1960, 82, 131-138.

[34] M. E. Flanagan, T. A. Blumenkopf, W. H. Brissette, M. F. Brown, J. M. Casavant, C. Shang-Poa, J. L. Doty, E. A. Elliott, M. B. Fisher, M. Hines, C. Kent, E. M. Kudlacz, B. M. Lillie, K. S. Magnuson, S. P. McCurdy, M. J. Munchhof, B. D. Perry, P. S. Sawyer, T. J. Strelevitz, C. Subramanyam, J. Sun, D. A. Whipple, P. S. Changelian, J. Med. Chem. 2010, 53, 84688484

[35] K. E. Price, C. Larrivee-Aboussafy, B. M. Lillie, R. W. McLaughlin, J. Mustakis, K. W. Hettenbach, J. M. Hawkins, R. Vaidyanathan, Org. Lett. 2009, 11, 2003-2006. 
WILEY-VCH

\section{MICROREVIEW}

\section{Entry for the Table of Contents}

\section{MICROREVIEW}

Tofacitinib is a Janus activated kinase (JAK) inhibitor approved for the treatment of rheumatoid arthritis and active psoriatic arthritis. Its synthesis normally involves long synthetic sequences due to the chirality associated to the piperidine ring. This review is a comprehensive analysis of the different synthetic methods used to prepare this active pharmaceutical ingredient (API), covering the related journal and patent literature.

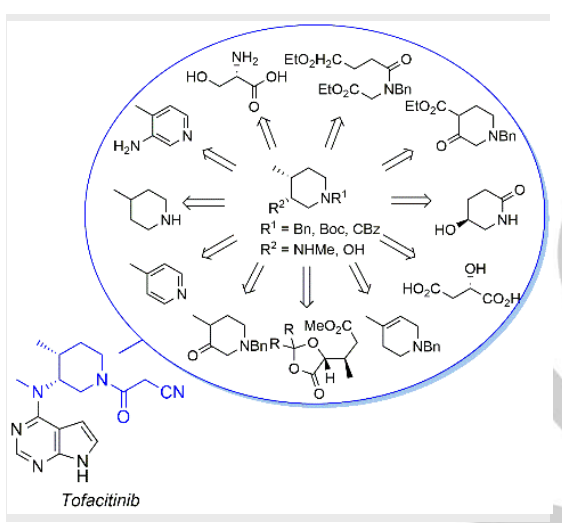

\section{Asymmetric synthesis}

Luísa C. R. Carvalho, *Ana Lourenço, Luísa Maria Ferreira and Paula Sério Branco

Page No. - Page No.

Tofacitinib synthesis - an asymmetric challenge 